\title{
O probiótico Saccharomyces boulardii modula a resposta de IgG2a em camundongos expostos aos antígenos de Leishmania infantum*
}

\section{Probiotic Saccharomyces boulardii modulates IgG2a response in mice exposed to Leishmania infantum antigens}

\author{
Joelson Sousa Lima, ${ }^{* *}$ Ana Paula Presley Oliveira Sampaio, ${ }^{* *}$ Flávio da Silva, ${ }^{* *}$ Maiara Vasconcelos Monteiro, ** \\ Isis Abel Bezerra, ${ }^{* *}$ Fabio Pereira Leivas Leite, ${ }^{* * *}$ Carina Martins de Moraes, ${ }^{* *}$ Talita Bandeira Roos ${ }^{* *}$
}

\begin{abstract}
Resumo
O objetivo do presente estudo foi avaliar os efeitos do probiótico Saccharomyces boulardii na modulação da resposta imune humoral de animais expostos a antígenos de Leishmania infantum. Para isso, 16 camundongos BALB/c foram imunizados com antígeno particulado de Leishmania infantum e divididos em dois grupos experimentais, um composto por animais suplementados e outro por animais não suplementados com o probiótico. Amostras de sangue dos animais foram colhidas semanalmente durante o período experimental e submetidas ao Ensaio da Imunoabsorbância Ligado à Enzima indireto para avaliação dos títulos de IgG totais e o perfil dos isotipos de $\lg G$ produzidos ( $\operatorname{lgG} 1$ e $\lg \mathrm{G} 2 \mathrm{a}$ ). A suplementação com o probiótico não exacerbou a produção de IgG total em comparação ao grupo controle, não havendo diferenças significativas entre os dois grupos. Porém, as soroconversões de IgG2a foram mais elevadas no grupo suplementado, no qual registrou-se um aumento de 1,46 vezes no final do experimento. Assim, a suplementação com $S$. boulardii foi capaz de modular a resposta de IgG2a/lgG1 nos animais expostos aos antígenos de Leishmania infantum.
\end{abstract}

Palavras-chave: leishmaniose, resposta imune, vacina.

\begin{abstract}
The aim of the present study was to evaluate the effects of the Saccharomyces boulardii probiotic on the modulation of humoral immune response in animals exposed to Leishmania infantum antigens. For this, $16 \mathrm{BALB} / \mathrm{c}$ mice were immunized with Leishmania infantum particulate antigen and divided into two experimental groups, one consisting of supplemented animals and the other not probiotic supplemented animals. Blood samples from the animals were taken weekly during the experimental period and subjected to the Indirect Enzyme-Linked Immunosorbance Assay for evaluation of total IgG titers and the profile of the produced $\lg G$ isotypes (IgG1 and IgG2a). Probiotic supplementation did not exacerbate total IgG production compared to the control group, with no significant differences between the two groups. However, IgG2a seroconversions were higher in the supplemented group, which showed a 1.46 -fold increase at the end of the experiment. Thus, supplementation with S. boulardii was able to modulate the IgG2a/lgG1 response in animals exposed to Leishmania infantum antigens.
\end{abstract}

Keywords: leishmaniasis, immune response, vaccine.

\section{Introdução}

A leishmaniose visceral é uma zoonose altamente preocupante em virtude dos sinais clínicos e gravidade variável que pode provocar, além do grande número de indivíduos suscetíveis (Gontijo e Melo, 2004; Diaz et al., 2012). Muitas estratégias têm sido adotadas a fim de se produzir imunobiológicos com capacidade de estimular respostas eficientes e duradouras frente ao parasito causador da doença (Thakur et al., 2015; Darabi et al., 2015; Martins et al., 2016). No entanto, as complexas interações estabelecidas entre Leishmania spp. e seus hospedeiros, sobretudo os mecanismos desenvolvidos por esses protozoários para se evadir da resposta imune, representam grandes entraves para a elaboração de vacinas (Diaz et al., 2012; Gradoni et al., 2015; Jain e Jain, 2015).

Muitos trabalhos têm discutido a importância de componentes do sistema imune para a progressão ou cura da doença em indivíduos naturalmente ou experimentalmente infectados, sintomáticos ou assintomáticos (Bhattacharyya et al., 2014;

* Recebido em 18 de abril de 2019 e aceito em 12 de dezembro de 2019

**Universidade Federal do Pará, Campus de Castanhal, Instituto de Medicina Veterinária, Castanhal, Pará, Brasil.

***Universidade Federal de Pelotas, Campus Capão do Leão, Centro de Desenvolvimento Tecnológico - CDTec, Pelotas, Rio Grande do Sul, Brasil.

Autor para correspondência: joelsonbio@live.com. 
Rostamian et al., 2015). Portanto, o papel da resposta dos anticorpos também é de suma importância para que se estabeleça um padrão de susceptibilidade ou proteção contra o parasito, no qual classes e subclasses de imunoglobulinas estão envolvidas no controle da multiplicação ou na persistência dos patógenos (Solano-Gallego et al., 2001).

Simultaneamente, avanços na identificação das propriedades terapêuticas e imunomoduladoras de probióticos despertam o interesse do uso desses bioativos na melhoria e modulação das respostas vacinais (Roos et al., 2010; Roos et al., 2012; Levast et al., 2015). Os probióticos compreendem formulações contendo micro-organismos vivos que em concentrações adequadas são responsáveis por desenvolverem efeitos benéficos à saúde do hospedeiro (Schrezenmeir e De Vrese, 2001).

Pesquisadores já comprovaram que a vacinação combinada à suplementação com probióticos melhora a resposta imune do hospedeiro frente ao antígeno ao qual foi estimulado. A esse respeito, convém mencionar os resultados de trabalhos com a levedura Saccharomyces boulardii, que indicaram incremento nas respostas inatas e adaptativas (Coppola et al., 2005; Lee et al., 2007; Roos et al., 2010; Ávila et al., 2016).

Nesse sentido, o presente trabalho teve como objetivo avaliar se a suplementação com o probiótico $S$. boulardii foi capaz de modular a resposta imune humoral de animais imunizados com antígeno particulado de Leishmania infantum, identificando o perfil de imunoglobulinas $\mathrm{G}$ secretado.

\section{Material e métodos}

Foram utilizados 16 camundongos da linhagem BALB/c albina, fêmeas com cerca de 21 dias de idade, oriundos do biotério central do Instituto Evandro Chagas, os quais foram mantidos sob temperatura de $22^{\circ} \mathrm{C}$ e ciclos de iluminação claro/escuro de $12 \mathrm{~h}$. Todos os procedimentos adotados neste estudo, bem como o manuseio dos animais, obedeceram a legislação brasileira (BRASIL, LEI No 11.794 de 8 de outubro de 2008) e seguiram as normas do Conselho Nacional de Controle e Experimentação Animal (CONCEA). Constando, ainda, da aprovação pelo Comitê de Ética de Experimentação Animal da Universidade Federal de Pelotas (UFPel), sob o protocolo $n^{\circ} 5758$.

Para o cultivo do probiótico adotaram-se os procedimentos descritos por Ávila et al. (2012), com modificações. A levedura foi cultivada em meio YPD (Levedura, Peptona e Dextrose), líquido e solidificado com $2 \%$ de ágar-base e incubada em estufa à temperatura de $28^{\circ} \mathrm{C}$. Após os procedimentos de centrifugação, lavagem, e contagem, a solução contendo o micro-organismo foi diretamente incorporada à ração. O controle da pureza foi realizado em todas as etapas do processo, por meio de esfregaço corado a partir da técnica de Gram e também se realizava a semeadura em ágar sangue e YPD.

A produção do antígeno particulado ocorreu a partir de formas promastigotas de $L$. infantum, em final de fase logarítmica. Inicialmente, a cultura foi submetida à centrifugação a 1540 x g a $4^{\circ} \mathrm{C}$, por $10 \mathrm{~min}$., seguida de duas lavagens em solução salina tamponada com fosfato (PBS) $0,1 \mathrm{M}, \mathrm{pH} 7,2$. O material foi submetido a cinco sequências de congelamento $\left(\mathrm{a}-80^{\circ} \mathrm{C}\right) \mathrm{e}$ aquecimento a $37^{\circ} \mathrm{C}$. Após a lise celular, o antígeno particulado foi ressuspenso em PBS e a dosagem de proteínas foi realizada pelo método de Bradford (Bradford, 1967). A suspensão contendo o antígeno foi diluída para uma concentração final de $1 \mathrm{mg} / \mathrm{mL}$ e, então, armazenada $-70^{\circ} \mathrm{C}$, até o uso.

Para a produção da vacina experimental, acrescentou-se $100 \mu \mathrm{l}$ da solução contendo o antígeno particulado em $1000 \mu \mathrm{L}$ de hidróxido de alumínio e o volume completado com $6000 \mu \mathrm{L}$ de PBS. A administração da vacina se deu por via subcutânea, com o volume de $100 \mu \mathrm{L}$ em cada animal. Foram realizadas quatro aplicações da vacina, nos dias sete, 21, 42 e 70 do período experimental.

Os animais foram divididos em dois grupos experimentais, sendo o grupo A (controle) aquele cujos os animais foram imunizados, mas não receberam o probiótico, enquanto que o grupo B foi composto pelos animais que além de vacinados foram suplementados de maneira contínua com S. boulardii, conforme os procedimentos realizados anteriormente por Roos et al. (2018).

A suplementação dos camundongos ocorreu mediante a administração do probiótico por via oral, incorporado à ração diária, na concentração de $10^{7} \mathrm{UFC} \cdot \mathrm{g}^{-1}$. O fornecimento da ração incrementada com o probiótico iniciou-se sete dias antes da primeira exposição ao antígeno de Leishmania sp. e foi suspenso no $56^{\circ}$ dia do experimento. Mesmo após a parada da suplementação o experimento se prolongou até o dia 84, a fim de que se avaliasse os efeitos de S. boulardii a longo prazo, após o término da suplementação.

Amostras de sangue de todos os animais foram colhidas semanalmente $(7,14,21,28,35,42,49,56,63,70,77$ e 84$)$, a partir do plexo venoso retro orbital com auxílio de pipeta Pasteur, com os animais anestesiados com Quetamina + Xilazina $(90 \mathrm{mg} /$ $\mathrm{kg}+5 \mathrm{mg} / \mathrm{kg}$ de peso, respectivamente) por via intraperitoneal. Após cada coleta, as amostras de sangue devidamente identificadas foram centrifugadas por $10 \mathrm{~min}$. a $12000 \mathrm{xg}$ para a separação do soro que foi transferido para outro microtubo, o qual foi identificado e armazenado a $-20^{\circ} \mathrm{C}$.

Para avaliação da cinética da produção de anticorpos adotouse o Ensaio da Imunoabsorbância Ligada à Enzima (ELISA) indireto, utilizando placas de poliestireno com 96 cavidades (Nunc PolySorp®), e seguiu-se o protocolo de Roos et al. (2012) para realização do teste, com algumas modificações.

Para sensibilização da placa utilizou-se $100 \mu \mathrm{L}$ de antígeno particulado, na concentração de $1 \mathrm{mg} / \mathrm{mL}$, diluído em Tampão Carbonato-Bicarbonato (TCB), pH 9,6, na diluição 1/100, sendo incubadas durante a noite à $4^{\circ} \mathrm{C}$. As placas foram lavadas três vezes com solução salina tamponada com fosfato, contento Tween 20 a 0,5\% (PBS-T), $\mathrm{pH} 7,6$.

Em seguida foram adicionados $100 \mu \mathrm{L}$ de solução contendo leite em pó desnatado Molico $®$ a $5 \%$, por 30 min., a temperatura ambiente, para que ocorresse o bloqueio das reações inespecíficas. Após o bloqueio, foram adicionados, em duplicata, $100 \mu \mathrm{L}$ de cada soro previamente diluídos (1/100) em PBS-T e incubadas por uma hora à $37^{\circ} \mathrm{C}$. Após esse período, as placas foram lavadas três vezes com PBS-T, seguido da adição de $100 \mu \mathrm{l}$ do conjugado de imunoglobulinas anti-camundongo ligadas à peroxidase, produzidas em cabras (Sigma Alderich 
A4416), diluído na proporção de 1/5000 em PBS-T, e incubadas por uma hora e meia à $37^{\circ} \mathrm{C}$.

Posteriormente, as placas foram lavadas cinco vezes com PBS-T e logo depois foram adicionados $100 \mu \mathrm{l}$ de substrato/cromógeno (Sigma FAST TM OPD), deixando reagir por $15 \mathrm{~min}$., no escuro, a temperatura ambiente. As absorbâncias foram medidas em filtro de $450 \mathrm{~nm}$ em um leitor de microplacas (Eon Biotek, Programa GEN 5) e divididas pela absorbância do soro da coleta 1 do mesmo animal, e os resultados expressos em soroconversão.

Para a identificação dos isotipos de IgG utilizouse 0 kit de reagentes ISO2- $1 \mathrm{KT}$ de anticorpos monoclonais de camundongo (Sigma-Aldrich ${ }^{\mathrm{TM}}$ ). Os procedimentos de sensibilização e bloqueio ocorreram de forma semelhante ao que foi realizado na identificação das IgGs totais. Os soros dos animais do mesmo grupo foram analisados em pool, de acordo com cada coleta. As amostras dos pools utilizadas foram diluídas na proporção de 1/100 e, após adicionadas, a placa incubada a $37^{\circ} \mathrm{C}$ durante $60 \mathrm{~min}$. e, em seguida, lavada três vezes com PBS-T.

Os anticorpos monoclonais anti-IgG de camundongo (anti-lgG1 e anti-lgG2a), produzidos em cabras, foram diluídos em PBS-T na proporção de $1 / 2000$, adicionados em duplicata e a placa foi incubada a $37^{\circ} \mathrm{C}$ por $30 \mathrm{~min}$. Depois disso, procedeu-se a lavagem e adicionou-se o conjugado de imunoglobulinas anti-cabra ligadas à peroxidase, previamente diluída para uma proporção de 1/4000, seguido de incubação por 15 min., a temperatura ambiente e mais três lavagens. Após essa etapa acrescentou-se as pastilhas de substrato para peroxidase e cromógeno Sigma Fast ${ }^{\mathrm{TM}}$ OPD P9187-50SET, Sigma -Aldrich ${ }^{\circledR}$, diluídas em $20 \mathrm{~mL}$ de água deionizada, conforme a orientação do fabricante, sendo adicionados $100 \mathrm{uL}$ dessa solução em cada cavidade da placa, seguido de incubação durante $15 \mathrm{~min}$. a temperatura ambiente, no escuro. Por fim, a reação foi parada com $\mathrm{H}_{2} \mathrm{SO}_{4}$ a $3 \%$ e a leitura realizada em leitor de microplacas, sob filtro de 450nm para aferir a absorbância.

As análises estatísticas descritiva e analítica, para isotipos e lgG total respectivamente, foram realizadas com auxílio dos softwares Microsoft Excel e SPSS v. 20. A análise de variância (ANOVA) foi aplicada para identificação de diferenças significativas entre os grupos. Quando presentes e as variâncias eram homogêneas, o teste de Tukey foi aplicado a posteriori, enquanto que o T3 de Dunnett foi empregado quando as variâncias não eram homogêneas. Todos os testes foram aplicados considerando o nível de significância de 5\%.

\section{Resultados e discussão}

Observou-se que a razão entre as soroconversões de lgG2a/ IgG1 foi mais representativa no grupo suplementado, isto é, IgG2a apresentou maiores títulos quando comparado ao grupo que não recebeu o probiótico, demonstrando, assim, o efeito modulador de $S$. boulardii associado à vacinação experimental (Figura 1).
As maiores soroconversões de $\operatorname{lgG} 2 a$ em razão de $\lg G 1$ no grupo suplementado foram registradas no final do experimento, nos dias 77 e 84, (sete e 14 dias após a última exposição ao antígeno). No dia 77 , os valores de IgG2a/lgG1 computados foram 1,40 e 0,95 nos grupos suplementado e não suplementado, respectivamente. Já no dia 84 , registrou-se aumento de 1,46 vezes de IgG2a em detrimento a IgG1, comparado com o primeiro dia da coleta, enquanto que no grupo que não recebeu suplementação a soroconversão no último dia do experimento foi de 0,93 vezes, demonstrando que mesmo após a suspensão do probiótico (dia 56) houve modulação da resposta de IgG2a nos animais.

No dia 21, 14 dias após a primossensibilização, identificou-se, em ambos os grupos, um aumento na produção de $\lg \mathrm{G} 2 \mathrm{a}$, sendo 1,24 de soroconversão no grupo suplementado e 1,05 no grupo que não recebeu $S$. boulardii. Além disso, durante as cinco primeiras semanas do experimento, observaram-se pequenas variações na razão das soroconversões que podem ser consequência de uma resposta indistinta entre lgG1 e lgG2a, indicando também uma resposta mista de Th1/Th2. Entretanto, depois do dia 35 o grupo suplementado apresentou aumento quase que constante na razão $\lg G 2$ a sem, no entanto, diminuir drasticamente os níveis de lgG1.

Considera-se que uma resposta eficiente contra Leishmania spp. compreende a ativação de vias que conduzem a uma resposta celular, com a presença de Linfócitos T CD4+ e CD8+, sendo os mais numerosos os linfócitos T auxiliares do subtipo 1 (Th1). Além disso, são necessários altos níveis de IL-12 e IFN-y, em detrimento da produção de IL-4, e com títulos menores de IL10 (Strauss-Ayali et al., 2007; Diaz et al., 2012; Grandoni et al., 2015). No que confere à resposta humoral, apenas IgG2a tem sido relacionada à resistência, ao passo que altos títulos de anticorpos inespecíficos são associados à susceptibilidade, a falhas nos mecanismos de contenção da replicação do parasito ou à infecção natural (Jain e Jain, 2013; Grandoni et al., 2015).

Com efeito, o perfil imunológico supracitado é o que tem sido descrito na literatura como necessário ao combate do parasito, 
e é o que se espera tanto em decorrência da administração de uma vacina quanto do uso de probióticos associados a esta. Assim, sugere-se que a suplementação com $S$. boulardii estimula a modulação de uma resposta mista Th1/Th2, com um predomínio de Th1, em virtude do aumento dos níveis de lgG2a.

Para Solano-Gallego et al. (2001), é possível, de maneira cuidadosa, relacionar a predominância de subclasses específicas de IgG com as respostas Th1 ou Th2. Além disso, esses mesmos autores acreditam no envolvimento de uma resposta mista (Th1-Th2) anti-Leishmania. Outros pesquisadores, como Jain e Jain (2015), também têm elucidado a importância desse perfil misto de resposta, visto que a resposta Th1 protege os animais, enquanto Th2 suporta a persistência da infecção. Tendo em vista tais afirmações, os resultados do presente estudo são contemplados com esse raciocínio, pois de acordo com a análise dos isotipos também é possível vislumbrar essa resposta mista nos animais suplementados.

Com respeito ao isotipo IgG1, essa subclasse é incriminada com o aumento das lesões em portadores sintomáticos e à exacerbação da doença, caracterizando dessa forma a leishmaniose progressiva, ao passo que baixos níveis desse anticorpo foram associados à proteção em camundongos. Por outro lado, a elevação de lgG2a em detrimento a lgG1 promove efeitos benéficos em camundongos infectados com Leishmania sp. (Rostamian et al., 2015).

No trabalho de Quinnel et al. (2003), cães com diagnóstico positivo para Leismania infantum, realizado por meio da reação em cadeia da polimerase (PCR), apresentaram níveis significativamente mais baixos de lgG2 em relação a lgG1. Nesse estudo, os animais doentes secretaram altos níveis das quatro IgGs pesquisadas (IgG1, IgG4, IgG3 e lgG2), porém o aumento de IgG2 foi menor do que das outras subclasses. Com base nisso, tais autores sugerem que IgG2 é regulado de maneira diferente das outras subclasses. Ademais, relataram que a razão lgG2/lgG1 foi diminuída em cães doentes. Comparativamente,

\section{Agradecimentos}

Ao CNPq pelo financiamento do projeto.

\section{Referências}

ÁVILA, L.F.C.; CONCEIÇÃO, F.R.; TELMO, P.L.; DUTRA G.F.; DE LOS SANTOS, D.G.; MARTINS, L.H.R., BERNA, M.E.; SILVA, P.E.; SCAINI, C.J. Saccharomyces boulardii reduces infection intensity of mice with toxocariasis. Vet Parasitol. v.187, p.337-40, 2012.

ÁVILA, L.F.C.; DE LEON, P.M.M.; DE MOURA, M.Q.; BERNE, M.E.A.; SACAINI, C.J.; LEITE, F.P.L.L. Modulation of IL-12 and INF-y by probiotic supplementation promotes protection against Toxocara canis infection in mice. Parasite Immunol. v. 38, p. 32630,2016

BHATTACHARYYA, T.; AYANDEH, A.; FALCONAR, A.K.; SUNDAR, S.; EL-SAFI, S.; GRIPENBERG, M.A.; BOWES, D.E.; THUNISSEN, C.; PRAKASH SINGH, O.M.; KUMAR, R.; AHMED, O.; EISA, O.; SAAD, A.; PEREIRA, S.S.; BOELAERT, M.; MERTENS, P.; MILES, M.A. IgG1 as a potential biomarker of post-chemotherapeutic relapse in visceral leishmaniasis, and adaptation to a rapid diganostic test. PLoS Negl Trop Dis. v. 8, p. 1-11, 2014. o uso e $S$. boulardii se apresentou promissor, uma vez que a resposta identificada nos camundongos suplementados com o probiótico caracteriza um perfil semelhante ao de cães assintomáticos ou que conseguem debelar a infecção.

Solano-Gallego et al. (2006) monitoraram durante 5 anos cães sintomáticos, assintomáticos infectados e não infectados quanto a presença de sinais clínicos e produção de lgG, IgG1, IgG2 contra $L$. infantum. Os resultados desses autores demonstraram que IgG2 esteve relacionada a animais assintomáticos enquanto IgG1 ao desenvolvimento da doença. Nos animais infectados assintomáticos houve uma baixa resposta de IgG1, até mesmo quando os níveis de IgG2 ou IgG total se elevaram ao longo do experimento.

Já com relação ao nível de IgG total, não houve diferença significativa $(p>0.05)$ entre os grupos. Estudos revelam que títulos elevados de anticorpos anti-Leishmania são considerados marcadores de susceptibilidade e de falha imunológica por favorecer um desvio para uma resposta do tipo Th2 (Rostamian et al., 2015).

Dessa maneira, os dados aqui apresentados mostram que a suplementação com S. boulardii não exacerbou a produção de anticorpos (IgG totais) com relação ao grupo controle, fato este considerado positivo no que diz respeito ao controle e prevenção da infecção por Leishmania spp., reiterando a possibilidade do uso do probiótico em questão. Além disso, notou-se que após a última dose da vacina o grupo suplementado apresentou um aumento no título de IgG total, todavia, comparado aos resultados da isotipagem, essa elevação condiz com a modulação de lgG2a.

\section{Conclusão}

Concluímos que a suplementação com S. boulardii provocou o aumento da razão lgG2a/lgG1 em camundongos expostos a antígenos particulados de Leishmania infantum.
BRADFORD, M.M. A Rapid and Sensitive Method for the Quantitation of Microgram Quantities of Protein Utilizing the Principle of Protein-Dye Binding. Anal Biochem. v. 72, n. 248-54, 1976.

CHABALGOITY, J.A.; BAZ, A.; RIAL, A.; GRILLE, S. The relevance of cytokines for development of protective immunity and rational design of vaccines. Cytokine Growth Factor Rev. v. 18, n. 195-207, 2007.

COPPOLA, M.M.; CONCEIÇÃO, F.R.; GIL-TURNES, C. Effect of Saccharomyces boulardii and Bacillus cereus var. toyoi on the humoral and cellular response of mice to vaccines. Food Agric Immunol. v. 16, n. 3, p. 213-219, 2005.

DARABI, S.; KHAZE, V.; RAD-RIAZI, F.; DARABI, H.; BAHRAMI, F.; AJDARY, S.; ALIMOHAMMADIAN, M.H. Leishmania major strains isolated from distinct endemic areas show diverse cytokine mRNA expression levels in C57BL/6 mice: Toward selecting an ideal strain for the vaccine studies. Cytokine. v. 76, p. 303-308, 2015. 
DIAZ, S.; DA FONSECA I.P.; RODRIGUES, A.; MARTINS, C.; CARTAXEIRO, C.; SILVA, M.J. Canine leishmaniosis. Modulation of macrophage/lymphocyte interactions by L. infantum. Vet Parasitol. v. 189, p. 137-144, 2012.

GONTIJO, C.M.F.; MELO, M.N. Leishmaniose Visceral no Brasil: quadro atual, desafios e perspectivas. Rev Bras Epidemiol. v. 7, n. 3, p. 338-349, 2004.

GRADONI, L. Canine Leishmania vaccines: Still a long way to go. Vet Parasitol. v. 208, p. 94-100, 2015.

JAIN, K.; JAIN, N.K. Vaccines for visceral leishmaniasis: A review. J Immunol Methods. v. 422, p. 1-12, 2015.

JAIN, K.; JAIN, N.K. Novel therapeutic strategies for treatment of visceral leishmaniasis. Drug Discov Today. v. 18, p. 23-24, 2013.

LEE, S.; LILLEHOJ, H.S.; PARK, D.W.; HONG, Y.H.; LIN, JJ. Effects of Pediococcus and Saccharomyces-based probiotic (MitoMaxs) on coccidiosis in broiler chickens. Comp Immun Microbiol Infect Dis. v. 30, p. 261-268, 2007.

LEVAST, B.; LI, Z.; MADRENAS, J. The role of IL-10 in microbiome-associated immune modulation and disease tolerance. Cytokine. 2015; 75: 291-301.

MARTINS, V.T.; LAGE, D.P.; DUARTE, M.C.; COSTA, L.E.; GARDE, E.; RODRIGUES, M.R.; CHÁVEZ-FUMAGALLI, M.A.; MENEZES-SOUZA, D.; ROATT, B.M.; TAVARES, C.A.; SOTO, M.; COELHO, E.A. A new Leishmania-specific hypothetical protein, $\mathrm{LiHyT}$, used as a vaccine antigen against visceral leishmaniasis. Acta Trop. v. 154, p. 73-81, 2016.

QUINNELL, R. J.; COURTENAY, O.; GARCEZ, L. M.; KAYE, P. M.; SHAW, M. A.; DYE, C.; DAY, M. J. IgG subclasse responses in a longitudinal study of canine visceral leishmaniasis. Vet Immunol Immunopathol. v. 91, p. 161-168, 2003.

ROOS, T.B.; TABELEÃO, V.C.; DÜMMER, L.A.; SCHWEGLER, E.; GOULART, M.A.; MOURA, S.V.; CORREAA, M.N.; LEITE, F.P.L.; GIL-TURNES, C. Effect of Bacillus cereus var. Toyoi and Saccharomyces boulardii on the immune response of sheep to vacines. Food Agric Immunol. v. 21, n. 2, p. 113-118, 2010.
ROOS, T.B.; DE LARAA.P.S.S.; DUMMER, L.A.; FISCHER, G.; LEITE, F.P.L. The immune modulation of Bacillus cereus var. Toyoi in mice immunized with experimental inactivated Bovine Herpesvirus Type 5. vaccine. Vaccine. v.30, p. 2173-2177, 2012.

ROSTAMIAN, M.; SOHRABI, S.; KAVOSIFARD, H.; NIKNAM, H.M. Lower levels of IgG1 in comparison with IgG2a are associated with protective immunity against Leishmania tropica infection in BALB/c mice. J Microbiol Immunol Infect. v. 50, n. 2, p. 160-166, 2017.

SCHREZENMEIR, J.; DE VRESE, M. Probiotics, prebiotics and symbiotics - approaching a definition. Am J Clin Nutri. v. 73, p. 361-364, 2001.

SOLANO-GALLEGO, L.; RIERA, C.; ROURA, X.; INIESTA, L.; GALLEGO, M.; VALLADARES, J.E.; FISA, R.; CASTILLEJO, S.; ALBEROLA, J.; FERRER, G.; ARBOIX, H.; PORTÚS, M . Leishmania infantum-especific IgG, IgG1 and IgG2 antibody responses in healthy and ill dogs from endemic áreas Evolution in the course of infection and after treatment. Vet Parasitol. v. 96, p. 265-276, 2001.

STRAUSS-AYALI, D.; BANETH, G.; JAFFE, C.L. Splenic immune responses during canine visceral leishmaniasis. Vet Res. v. 38, p. 547-564, 2007.

THAKUR, A.; KAUR, H.; KAUR, S. Evaluation of the immunoprophylactic potential of a killed vaccine candidate in combination with different adjuvants. Parasitol Int. v. 64, p. 70-78, 2015.

VITORIANO-SOUZA, J.; MOREIRA, N.D., MENEZES-SOUZA, D.; ROATT, B.M., AGUIAR-SOARES, R.D.O.; SIQUEIRA-

MATHIAS, F.A.; OLIVEIRA CARDOSO, J.M.; GIUNCHETTI, R.C.; SÁ, R.G.; CORREAA-OLIVEIRA, R.; CARNEIRO, C.M.; REIS, A.B. Dogs immunized with LBSap vaccine displayed high levels of IL-12 and IL-10 cytokines and CCL4, CCL5 and CXCL8 chemokines in the dermis. Mol Immunol. v. 56, p. 540-8, 2013. 